\title{
Clinical outcomes of newborn screening for cystic fibrosis
}

Donna L Waters, Bridget Wilcken, Les Irwig, Peter Van Asperen, Craig Mellis, Judy M Simpson, John Brown, Kevin J Gaskin
James Fairfax Institute of Paediatric Nutrition Royal Alexandra Hospital for Children, Sydney,

PO Box 3515

Parramatta 2124,

New South Wales,

Australia

D L Waters

K J Gaskin

Department of Biochemical Genetics B Wilcken

Department of Respiratory Medicine $P$ Van Asperen

C Mellis

J Brown

Department of Public Health,

University of Sydney

L Irwig

J M Simpson

Correspondence to: Professor K J Gaskin.

Accepted 11 August 1998

\begin{abstract}
Aim-To determine how early diagnosis of cystic fibrosis, using neonatal screening, affects long term clinical outcome.

Methods-Fifty seven children with cystic fibrosis born before neonatal screening was introduced (1978 to mid 1981) and a further 60 children born during the first three years of the programme (mid 1981 to 1984), were followed up to the age of 10 . The cohorts were compared on measures of clinical outcome, including height, weight, lung function tests, chest $x$-ray picture and Shwachman score.

Results-Age and sex adjusted standard deviation scores (SDS) for height and weight were consistently higher in children screened for cystic fibrosis than in those born before screening. At 10 years of age, average differences in SDS between groups were $0.4(95 \%$ CI $-0.1,0.8)$ for weight and $0.3(95 \%$ CI $-0.1,0.7)$ for height. This translates to an average difference of about $2.7 \mathrm{~cm}$ in height and 1.7

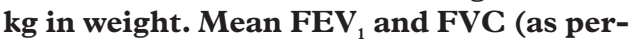
centage predicted) were significantly higher in the screened cohort at 5 and $\mathbf{1 0}$ years of age, with an average difference of 9.4\% $\mathrm{FEV}_{1}(95 \% \mathrm{CI} 0.8,17.9)$ and $8.4 \%$ FVC $(95 \%$ CI $1.8,15.0)$ at 10 years. Chest $\boldsymbol{x}$-ray scores were not different between the groups at any age, but by 10 years screened patients scored an average 5.3 (95\% CI 1.2, 9.4) points higher on the Shwachman score.

Conclusion-Although not a randomised trial, this long term observational study indicates that early treatment made possible by neonatal screening may be important in determining subsequent clinical outcomes for children with cystic fibrosis. For countries contemplating the introduction of neonatal screening for cystic fibrosis, its introduction to some areas in a cluster randomised design will permit validation of studies performed to date. (Arch Dis Child Fetal Neonatal Ed 1999;80:F1-F7)
\end{abstract}

Keywords: cystic fibrosis; neonatal screening; early diagnosis; clinical outcomes
Neonatal screening programmes for the common genetic disorder, cystic fibrosis (CF), have been developed and implemented in many centres over the past 25 years on the premise that early diagnosis and pre-symptomatic treatment improve clinical outcome. ${ }^{1}$ Diagnosis of CF in the newborn period has permitted detailed investigation into the early natural history of this condition, ${ }^{2}$ and programmes for screening ${ }^{3-6}$ seem to be comparable with others used for neonatal detection of disease. However, concerns have been expressed about possible harm to early parent-child relationships from newborn screening programmes for $\mathrm{CF}^{7-9}$ and strategies for communicating screening test information to parents have been problematic in some regions. ${ }^{10} 11$

Previous observational studies suggest generally favourable short term outcomes from neonatal screening for CF. Prevention of nutritional deficits, ${ }^{12-14}$ the early detection and treatment of pancreatic disease, ${ }^{6}$ and reduced morbidity and inpatient stay in the first two years of life ${ }^{15}$ have been reported. Significantly better outcomes for screened infants have also been reported in two long term observational studies. In one, however, results are complicated by non-standardisation of methods, with increasing proportions of infants joining the programme over the 15 year follow up period. ${ }^{16}$ In another, ${ }^{17}$ a total of only 13 cases were available for comparison at 10 year follow up. Two randomised controlled trials of neonatal screening for CF have been conducted in the USA and UK, but both have failed to demonstrate conclusively long term benefits. In the $\mathrm{UK}$ trial $^{18}$ incomplete ascertainment of CF cases within the non-screened population probably occurred, while in the US study, ${ }^{19-21}$ only four children in the early diagnosis group and nine controls were available for follow up at 10 years of age. ${ }^{21}$ Furthermore, pre-diagnosis anthropometric data were not available for the control group. Therefore, analysis at earlier ages omitted around 35\% of infants (possibly those with less severe disease), violating the "intention to treat" principle of randomised controlled trial analysis. Until such methodological issues are addressed, long term benefits attributed to children receiving early treatment for CF can only be speculative. The reporting of accumulated long term observa- 
tional or cohort data is therefore important to the ongoing debate.

The State of New South Wales (NSW) in Australia screens over 90000 infants a year and has tested neonates for CF since July 1981. Although screening was not introduced in a randomised controlled trial, the size of the programme and its longevity mean that a longitudinal 10 year follow up of a cohort of screened infants diagnosed with $\mathrm{CF}$ can be undertaken. These children were compared with an historical control group of similarly treated infants born before screening was introduced, to determine whether early diagnosis was associated with any long term benefits for outcomes such as respiratory function and growth.

\section{Methods}

An historical cohort study comparing a group of 57 patients with CF born in the three years immediately before the NSW Newborn Screening Programme was introduced (July 1978 to July 1981; "non-screened") with 60 infants born during the first three years of this programme (July 1981 to July 1984; "screened"). Both groups comprise those infants born in NSW who were referred to the CF Clinic at the Royal Alexandra Hospital for Children, Sydney, and who were diagnosed before October 1995. Referral to this clinic is based on physician network and geographic proximity, with attendance by about $60 \%$ of all new cases of CF diagnosed in NSW. The statewide percentage for all children with $\mathrm{CF}$ referred to the centre was the same in both groups, as referral patterns did not change with the introduction of the screening programme.

Excluded from the study were three children in the screened group who transferred to clinics in other states before 12 months of age. Patients transfer between clinics primarily to attend the one closest to their place of residence. Seventeen of the children (7 screened, 10 non-screened) transferred to a new CF clinic opened in western Sydney in 1982 for this reason. These children remain in the cohort and were included in the analysis. Inpatient rates and length of stay for CF related illness have been reported before for this cohort which in 1985 comprised infants aged 2 years or more. ${ }^{15}$

In the current study, groups were compared on measures of clinical status up to 10 years of age. During the study period, neonatal screening was performed using dried blood immunoreactive trypsin (IRT) assay which was repeated if raised. Infants with persistently raised IRT were referred for sweat testing to confirm the diagnosis of $\mathrm{CF} .{ }^{1}$ The false positive rate of this test protocol was between five and six per cent.

The study was approved by the ethics committees of the Royal Alexandra Hospital for Children and the University of Sydney.

Changes to patient management throughout the 16 years of the study (apart from the introduction of neonatal screening) were the gradual phasing out of low fat diets, beginning 1981-2, the introduction of new generation pancreatic enzyme replacement treatment (en- teric coated microspheres) from 1982-3, and the regular attendance of a paediatric gastroenterologist (KG) at both the Sydney and western Sydney clinic from mid 1983. These changes were not introduced homogenously, as individual differences in physician, parent, and patient acceptance dictated treatment preferences over a period of years. The use of nebulised antibiotics has been a feature of outpatient management since 1988, its use applying equally to both groups. No other major changes to staff, treatment philosophy, antibiotic or chest treatments occurred during each patient's 10 year follow up period.

MEASURES OF CLINICAL OUTCOME

Apart from visits for ill health, clinic patients routinely attend an interval medical check on (or around) each birthday and every six months inbetween. In this study routinely collected data on lung function, nutritional status, and growth recorded at diagnosis and closest to the first, fifth, and tenth birthdays were retrieved from each patient's medical record. Measures of clinical outcome include height, weight, chest $x$-ray score, Shwachman clinical score and (in children able to perform reliable pulmonary function testing) forced expiratory volume in one second $\left(\mathrm{FEV}_{1}\right)$, forced expiratory flow rate in the middle half of forced vital capacity $\left(\mathrm{FEF}_{25-75}\right)$, and forced vital capacity (FVC). Lung function measures are expressed as a percentage of predicted normal values for height and sex. ${ }^{22}$ The presence of symptoms at diagnosis was transcribed from the physician's record of the first clinic visit. For the 100 children continuing to receive care at the original referral centre during the 10 years of follow up, height (in centimetres) and weight (in kilograms) were measured on the same stadiometer and scales over the period. Variables not recorded or not measured at the designated times are coded as missing values.

Anthropometric variables were converted to age and sex appropriate standard deviation scores (SDS) for height and weight using the method of Dibley et al. ${ }^{23}$ Pancreatic function was determined by fecal fat estimation and/or pancreatic stimulation tests, as described before $^{6}$ in $40(67 \%)$ of the screened and 15 $(26 \%)$ of the non-screened children. We assumed pancreatic insufficiency - that is, the presence of malabsorption - in seven patients (3 screened, 4 non-screened) born with meconium ileus. Four of the remaining 55 patients (2 screened, 2 non-screened) were categorised as pancreatic sufficient (PS) on the basis of a normal serum pancreatic isoamylase and/or no reported symptoms of malabsorption and normal growth without pancreatic enzyme replacement treatment for varying periods between diagnosis and five years. A further five screened and 19 non-screened patients were classified as pancreatic insufficient (PI) after 2 years of age on the basis of low pancreatic isoamylase measurements, as defined before. ${ }^{6}$ In the absence of definitive testing the remaining 27 patients (10 screened, 17 non-screened) were classified as PI on the basis of clinical symptomatology (oily stools and poor growth), 
Table 1 Comparison of screened and non-screened birth cohorts

\begin{tabular}{|c|c|c|c|}
\hline & $\begin{array}{l}\text { Screened } \\
(n=60)\end{array}$ & $\begin{array}{l}\text { Non-screened } \\
(n=57)\end{array}$ & $p$ Value \\
\hline Male:female & $34: 26$ & $29: 28$ & 0.5 \\
\hline Meconium ileus & 7 & 6 & 0.8 \\
\hline \multicolumn{4}{|l|}{ Age of diagnosis (months) } \\
\hline Median (range) & $1.8(0.1-81.0)$ & $5.7(0.1-51.5)$ & $<0.0001$ \\
\hline Excluding meconium ileus & $1.8(0.1-81.0)$ & $6.2(1.1-51.5)$ & $<0.0001$ \\
\hline Excluding 3 patients missed by screening ( $n=57$ ) & $1.8(0.1-7.6)$ & & \\
\hline \multicolumn{4}{|l|}{ Pancreatic function } \\
\hline PS:PI at diagnosis & $16: 44$ & $6: 51$ & 0.03 \\
\hline PS becoming PI & 10 & 3 & 0.6 \\
\hline Symptoms at diagnosis (including meconium ileus) & 30 & 56 & $<0.0001$ \\
\hline \multicolumn{4}{|l|}{ Height SDS at diagnosis } \\
\hline Combined mean (SD) & $-0.2(1.6)$ & $-1.2(1.6)$ & 0.006 \\
\hline Pancreatic sufficient [PS] & $-0.4(1.4)$ & $-0.06(0.9)$ & \\
\hline Pancreatic insufficient [PI] & $-0.2(1.7)$ & $-1.4(1.7)$ & \\
\hline \multicolumn{4}{|l|}{ Weight SDS at diagnosis } \\
\hline Combined mean (SD) & $-0.1(1.4)$ & $-1.2(1.4)$ & $<0.0001$ \\
\hline Pancreatic sufficient [PS] & $0.3(0.9)$ & $0.1(0.9)$ & \\
\hline Pancreatic insufficient [PI] & $-0.2(1.6)$ & $-1.3(1.3)^{\star}$ & \\
\hline Deaths due to CF & 1 & 4 & 0.2 \\
\hline Total lost to follow up (includes deaths and transfers) & 10 & 17 & 0.1 \\
\hline
\end{tabular}

SDS $=$ standard deviation score; $\mathrm{SD}=$ standard deviation; Students $t$ test: ${ }^{\star} \mathrm{p}<0.01$ for difference in SDS between PS and PI.

requiring treatment with pancreatic enzyme replacement.

\section{ANALYSIS OF DATA}

Cross sectional results at diagnosis, 1, 5, and 10 years of age are given as mean and standard deviation (SD) or median and range for the total sample of 117 children: 60 screened and 57 non-screened. Three children in the screened group were missed by the screening test but were included in the analysis of this group from the time of their diagnosis (analysis by intention to screen). Their inclusion did not alter the findings. As anthropometric variables are standardised for age (standard deviation score or SDS), all patients were included in the cross sectional analysis at diagnosis regardless of their age at diagnosis. Similarly, 11 patients diagnosed between 12 and 18 months of age, including two cases missed by screening and eight non-screened (median age of diagnosis 1.3 years), are incorporated into the cross sectional analysis at 1 year. Apart from these exceptions, all other data are from the annual interval medical check performed on (or around) the first, fifth, and tenth birthdays.

Comparison between cohorts was done using Student's $t$ test for normally distributed variables, Mann-Whitney $U$ test for nonnormally distributed variables, or the $\chi^{2}$ test (Fisher's exact test for expected cell size $<5$ ) for categorical variables. Standard regression techniques using MINITAB Statistical Software (Minitab Inc, State College, PA, USA) were used to compare the cohorts while adjusting for individual patient differences, such as gender, presentation with meconium ileus, or pancreatic function. Estimates of the mean difference between groups (positive values indicate magnitude of advantage to screened group) are given with $95 \%$ confidence intervals (CI).

Longitudinal comparison of outcome variables for children remaining in the cohort to 10 years of age was by generalised estimating equations $^{24}$ (GEE) using SPIDA (Statistical Computing Laboratory, Eastwood, NSW, Australia). The GEE analysis allows all data at the three time periods to be used, even when a measurement is missing for that child at another time. A two dependence correlation structure was assumed, allowing for a common correlation at consecutive time points, but a different (always smaller) correlation between one and 10 year measurements.

\section{Results}

The birth cohorts are compared in table 1 . The screened group includes 57 infants referred directly after notification of raised IRT plus three infants missed by the screening programme, and aged $1.3,1.4$, and 6.8 years at diagnosis $(n=60)$. The median age of diagnosis was significantly lower in screened patients whether those born with meconium ileus are included or excluded (table 1). In the nonscreened group $(n=57) 53 \%$ of patients were diagnosed before 6 months of age, $70 \%$ before 12 months, and $91 \%$ by 2 years. Eighteen $(32 \%)$ of the non-screened group (aged between 4 months and 4 years) were diagnosed and started treatment during the screening phase of the study (after July 1981). The screened and non-screened groups were not significantly different with respect to the proportion of boys, babies born with meconium ileus, number of pancreatic sufficient (PS) patients becoming pancreatic insufficient (PI), or number of children lost to follow up (including transfers out and deaths) over the 10 years of the study. For children transferring to the western Sydney clinic, the average age of transfer was 2.3 and 3.7 years for seven screened and 10 non-screened patients, respectively.

CROSS SECTIONAL OUTCOMES

As expected, symptoms were present at diagnosis in a significantly higher proportion of non-screened infants (the one asymptomatic child was referred after diagnosis of CF in a sibling). For screened infants, gastrointestinal and respiratory symptoms were recorded at diagnosis in $22(36 \%)$ and $8(13 \%)$, respectively. Height and weight SDS show that

Table 2 Cross sectional anthropometry by age and pancreatic function: mean (SD)

\begin{tabular}{|c|c|c|c|}
\hline & $N=$ & Height SDS & Weight SDS \\
\hline \multicolumn{4}{|l|}{ One year } \\
\hline Screened & 57 & $-0.4(1.0)$ & $-0.1(0.9) \neq$ \\
\hline PS & 11 & $0.1(1.1) \oint$ & $-0.1(0.9)$ \\
\hline PI & 46 & $-0.5(0.9)$ & $-0.1(0.9)$ \\
\hline Non-screened & 48 & $-0.8(1.2)$ & $-0.6(1.1)$ \\
\hline PS & 4 & $0.6(0.9)^{\star}$ & $0.5(0.6)^{\star}$ \\
\hline PI & 44 & $-0.9(1.2)$ & $-0.7(1.1)$ \\
\hline \multicolumn{4}{|l|}{ Five years } \\
\hline Screened & 51 & $-0.1(1.0) \dagger$ & $0.1(1.1)$ \\
\hline PS & 6 & $0.5(1.2)$ & $0.1(1.1)$ \\
\hline PI & 45 & $-0.2(1.0)$ & $0.1(1.1)$ \\
\hline Non-screened & 52 & $-0.5(1.0)$ & $-0.3(1.0)$ \\
\hline PS & 4 & $0.3(0.4)$ & $0.4(0.4)$ \\
\hline PI & 48 & $-0.6(1.0)$ & $-0.3(1.0)$ \\
\hline \multicolumn{4}{|l|}{10 years } \\
\hline Screened & 51 & $-0.1(1.1) \dagger$ & $-0.2(0.9)$ \\
\hline PS & 6 & $0.3(1.2)$ & $0.1(1.3)$ \\
\hline PI & 45 & $-0.2(1.0)$ & $-0.2(0.8)$ \\
\hline Non-screened & 41 & $-0.6(0.9)$ & $-0.5(0.9)$ \\
\hline PS & 3 & $0.1(0.5)$ & $0.2(0.4)$ \\
\hline PI & 38 & $-0.6(0.9)$ & $-0.6(0.9)$ \\
\hline
\end{tabular}

SDS = standard deviation score; PS = pancreatic sufficient; PI $=$ pancreatic insufficient. Student's $t$ test: $\dagger \mathbf{p}<0.05$ and $\mathbf{p}<0.01$ for difference in SDS between screened and non-screened group. $\int \mathrm{p}<0.05$ and ${ }^{\star} \mathrm{p}<0.01$ for difference in SDS between PS and PI. 
Table 3 Mean differences between screened and non-screened group: cross sectional (CS) and longitudinal (L) data adjusted for pancreatic function (positive values indicate advantage for screened)

\begin{tabular}{|c|c|c|c|c|}
\hline & $\begin{array}{l}\text { One year } \\
\text { Mean }(95 \% \text { CI) difference } \\
\text { of estimate }\end{array}$ & $\begin{array}{l}\text { Five years } \\
\text { Mean ( } 95 \% \text { CI) difference } \\
\text { of estimate }\end{array}$ & $\begin{array}{l}10 \text { years } \\
\text { Mean }(95 \% \text { CI) difference } \\
\text { of estimate }\end{array}$ & $\begin{array}{l}\text { All ages (95\% CI) } \\
\text { unadjusted }\end{array}$ \\
\hline \multicolumn{5}{|c|}{ Height SDS } \\
\hline CS & $0.3(-0.1,0.7)$ & $0.4+(0.1,0.8)$ & $0.4(-0.1,0.8)$ & \\
\hline $\mathrm{L}$ & $0.2(-0.3,0.7)$ & $0.4(-0.1,0.8)$ & $0.4(-0.1,0.8)$ & $0.3(-0.1,0.7)$ \\
\hline \multicolumn{5}{|c|}{ Weight SDS } \\
\hline $\mathrm{CS}$ & $0.5 \ddagger(0.2,1.0)$ & $0.4(-0.1,0.8)$ & $0.3(-0.1,0.7)$ & \\
\hline $\mathrm{L}$ & $0.5+(0.1,0.9)$ & $0.2(-0.2,0.7)$ & $0.3(-0.1,0.7)$ & $0.4 \dagger(0.1,0.7)$ \\
\hline \multicolumn{5}{|c|}{$\mathrm{FEV}_{1}(\%$ predicted $)$} \\
\hline CS & & $9.0 \ddagger(2.6,15.4)$ & $9.4 \dagger(0.8,17.9)$ & \\
\hline $\mathrm{L}$ & & $7.3+(0.4,14.3)$ & $8.3(-0.1,16.6)$ & $8.6 \ddagger(2.1,15.0)$ \\
\hline \multicolumn{5}{|c|}{ FVC (\% predicted) } \\
\hline $\mathrm{CS}$ & & $8.5+(1.9,15.2)$ & $8.4+(1.8,15.0)$ & \\
\hline $\mathrm{L}$ & & $4.1(-2.4,10.7)$ & $7.3+(1.1,13.5)$ & $6.5 \dagger(1.0,11.9)$ \\
\hline \multicolumn{5}{|c|}{$\mathrm{FEF}_{25-75}(\%$ predicted $)$} \\
\hline $\mathrm{CS}$ & & $21.2 \ddagger(9.0,33.4)$ & $9.3(-5.7,24.2)$ & \\
\hline $\mathrm{L}$ & & $19.3 \ddagger(5.8,32.9)$ & $8.0(-7.1,23.1)$ & $13.2 \dagger(1.6,24.7)$ \\
\hline \multicolumn{5}{|c|}{ CXR score } \\
\hline CS & $1.0(-0.4,1.9)$ & $1.2(-0.1,2.6)$ & $1.0(-1.0,2.5)$ & \\
\hline $\mathrm{L}$ & $1.0(-0.4,2.2)$ & $1.1(-0.4,2.6)$ & $1.0(-1.2,2.4)$ & $1.0(-0.1,1.9)$ \\
\hline \multicolumn{5}{|c|}{ Shwachman score } \\
\hline CS & $2.4 \ddagger(0.7,4.1)$ & $3.8 \ddagger(1.0,4.1)$ & $5.3+(1.2,9.4)$ & \\
\hline $\mathrm{L}$ & $2.3+(0.4,4.1)$ & $2.8(-0.3,6.0)$ & $5.0+(0.8,9.2)$ & $3.6 \ddagger(1.4,5.7)$ \\
\hline
\end{tabular}

SDS = standard deviation score. Student's $t$ test: $\dagger \mathbf{p}<0.05$ and $\ddagger \mathbf{p}<0.01$ for difference between screened and non-screened group.

children referred from the screening programme were both longer and heavier at diagnosis than the non-screened children, after adjusting for age and sex. These differences remained significant after adjustment for the presence of symptoms (including meconium ileus) and for pancreatic function. There were

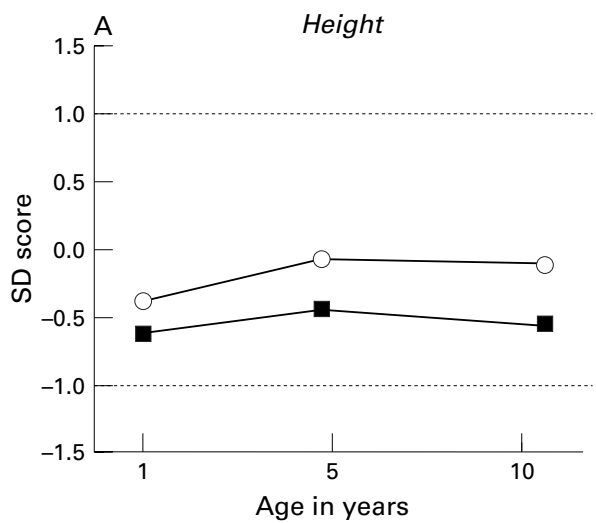

significantly more screened than non-screened infants who were PS at diagnosis, but for those diagnosed early by screening, no significant size difference was apparent between the PS and PI. For the non-screened group, however, six PS infants were significantly heavier than those categorised as PI at diagnosis (table 1).

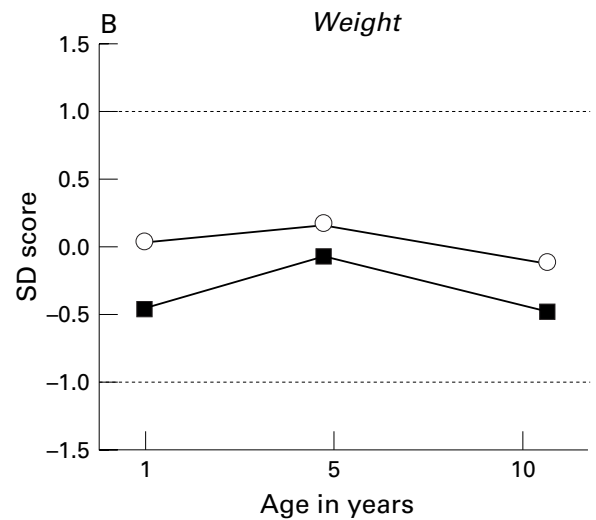

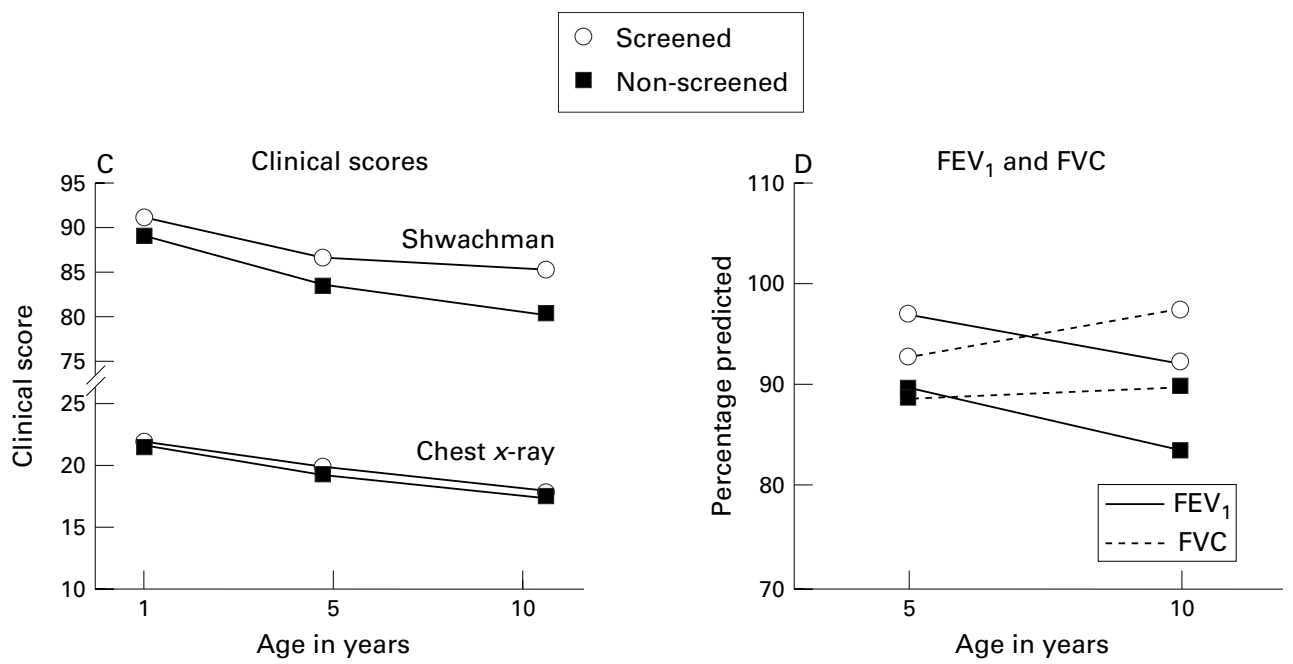

Figure 1 Longitudinal group data for screened and non-screened patients at 1, 5, and 10 years of follow up. Mean SD scores are shown for height $(A)$ and weight $(B)$; clinical scores for Shwachman and chest radiograph $(C)$ and $F E V$, and FVC, as percentage predicted (D). 
Table 2 shows cross sectional anthropometric data for the screened and non-screened group at each study age, stratified by pancreatic function (PS or PI) within each group. The mean (SD) age at each occasion of study was $1.1(0.21)$ years, $5.0(0.25)$ years, and 10.0 (0.29) years. At 1 year, screened patients remained significantly heavier, but were not significantly taller than the non-screened patients (table 2). A height advantage was apparent for PS patients within the screened group, while in the non-screened group at this age, both height and weight SDS were significantly greater in infants with PS. At 5 years, screened patients were significantly taller than the non-screened patients (table 2), but differences in weight SDS were no longer significant. PS remained a significant predictor of height at 5 years, but only six screened and four nonscreened children retained pancreatic function, and intragroup anthropometric differences due to PS were not significant. At 10 years of age, the significant height advantage for screened patients represented an average difference of about $2.7 \mathrm{~cm}$ in height and an average (but not significant) difference of around $1.7 \mathrm{~kg}$ in weight.

The mean differences between scores for the screened and non-screened patients (adjusted for pancreatic function) are shown for the cross sectional and longitudinal group data at each age in table 3. While anthropometric results remained consistent with those shown in table 2, adjusting for PS reduced the mean difference in height SDS at 10 years, which was no longer significant in table 3 .

All measured parameters of lung function were significantly higher in the screened cohort at 5 years of age, and by 10 years, there was an average difference of $9.4 \%$ in the predicted value of $\mathrm{FEV}_{1}$ and of $8.4 \%$ in the predicted value of FVC, in favour of the screened group. While the average chest radiograph score was similar for screened and non-screened groups at any age (table 3), the combined Shwachman Score was an average 5.3 points higher in the screened group by 10 years of age (mean Shwachman Score 86).

LONGITUDINAL OUTCOMES

The anthropometry of the 51 screened patients remaining in the cohort for 10 years was not significantly different from a normal reference population 50 th percentile ${ }^{25}$ with mean height SDS of $-0.1(95 \% \mathrm{CI}-0.4,0.2)$ and mean weight SDS of $-0.1(95 \%$ CI $-0.4,0.1)$. In contrast, the 41 non-screened patients were significantly below reference normal values, with a mean height SDS of -0.5 (95\% CI -0.9 to $-0.3, \mathrm{p}=0.0006)$ and mean weight SDS $-0.5(95 \% \mathrm{CI}-0.8,-0.2, \mathrm{p}=0.001)$. Analysis of all 92 patients in the longitudinal cohort at 1,5 , and 10 years of age confirms significant differences between groups, favouring the screened cohort for weight SDS $(p=0.02)$ and Shwachman Score $(p=0.001)$, but there were no significant differences in height SDS $(p=0.1)$ or chest $x$-ray score $(p=0.7)$. The magnitude of the difference between groups did not change significantly over time, based on tests of interaction between group and time (figs $1 \mathrm{~A}-\mathrm{C}$ ). As expected, mean $\mathrm{FEV}_{1}$ declined in both groups over time, but the magnitude of the differences between groups for both mean $\mathrm{FEV}_{1}$ and FVC were similar to those found in the cross sectional data (fig 1D). An estimate of the size of the differences between groups over all ages is given in table 3 .

\section{Discussion}

This study comprises one of the largest systematic longitudinal comparisons of outcomes between screened and non-screened patients receiving treatment at the same CF facility over an extended period. The screened and unscreened groups were comparable in size, as the numbers were not different (57 and 60) for each of the three year periods. In addition, the groups were also comparable in terms of the severity of disease, as at 5 and 10 years the proportion with pancreatic sufficiency was similar (table 2). The results of both the crosssectional and longitudinal analyses suggest that early treatment following diagnosis of CF by neonatal screening may improve the clinical outcome of patients during the first 10 years of life.

Examination of clinic policy revealed uniform respiratory management over the follow up period. Prophylactic flucloxacillin was used in the first year after diagnosis with oral, inhaled, and intravenous antibiotics for treatment of chest infections. Nutritional management did change in the early phase of this study with the gradual introduction of normal fat diets in 1981-2 and a change over to microspheric forms of enzyme replacement from 1982-3. While it is conceivable that the $80 \%$ of non-screened infants born before 1983 may have been disadvantaged by varying periods of low fat diets and changes to pancreatic enzyme replacement, two factors argue against this. Firstly, the non-screened group were older at diagnosis and would have received normal milk based infant and toddler diets before diagnosis. After diagnosis relatively short periods of dietary restriction would have been imposed and treatment with (nonmicrospheric) enzymes begun. Moreover, 32\% of the non-screened group were diagnosed after the screening programme had begun, and in addition to a normal diet before diagnosis, they continued to receive the same (nonrestricted) diet and pancreatic enzyme replacement after diagnosis as the screened group. Secondly, while all screened infants continued their normal milk based diet after diagnosis, those born during the first year of screening $(36 \%)$ were treated with the same (nonmicrospheric) forms of pancreatic enzymes as the non-screened children. Thus, if the type of enzyme had contributed to the observed differences in growth, then one would also expect to see some detrimental effect on the growth of screened infants in their first year. The results of this study suggest that this did not occur. The interaction of time, age of diagnosis, and individual differences in physician, patient, and parent acceptance during change over periods renders it unlikely that differences in growth 
between the screened and non-screened groups could be directly attributed to these changes in clinic policy.

Clearly, the screened group also had a higher proportion of patients with PS at the time of diagnosis. Pancreatic sufficient patients have been described as having milder disease phenotypes $^{26}$ and this may contribute to the more favourable outcome of screened patients. Statistical adjustments were therefore made to control for the clinical superiority of PS patients in both groups. Furthermore, we have already shown that, at the time of neonatal screening diagnosis, the proportion of patients with PS was much higher than in older CF populations - that is, patients with PS lose their pancreatic function over time and develop PI. ${ }^{6}$ A higher proportion of PS patients in the screened group would therefore be expected due to their younger age of diagnosis. In the current study, loss of pancreatic function over time was such that by 10 years of age, as stated above, the screened and non-screened groups had the same proportion of PS patients.

Other hidden or less quantifiable effects may have contributed to patient outcomes, including physician and parental perceptions of the screened versus non-screened infants. Inpatient stays were lower in the screened patients during their first two years of life, ${ }^{15}$ and while this could indicate that the non-screened group received more aggressive treatment, it is difficult to conceive how this would be disadvantageous in the long term. Finally, our population of CF patients represented $60 \%$ of the cases diagnosed statewide. Referral to clinics in NSW is based mainly on geographic factors. The three CF clinics in NSW are located at three paediatric teaching hospitals and the established referral patterns of local paediatricians depend almost entirely on their attachment to one of these three hospitals. As referral patterns did not change with the introduction of newborn screening, it is unlikely that referral of "milder" cases occurred during the screening period. The comparability of numbers in each patient group and their similarity on indicators of disease severity, such as the proportion with meconium ileus and PS, also support unbiased referral. We believe ascertainment in the cohorts studied is complete. All patients were over 10 years of age and the screening programme has a policy of actively seeking missed cases through regular contact with clinics in NSW and interstate, and with the major laboratories conducting sweat tests.

This study was not a randomised controlled trial and the non-screened comparison group was drawn from historical controls. Despite these limitations, the study is unique in the relatively large numbers of patients available for study at 10 year follow up. The results support an early nutritional and pulmonary function advantage to screened infants and suggest that initial benefits may be maintained over time. These results agree with those of previous controlled trials ${ }^{18}{ }^{21}$ and observational studies $^{16} 17$ which despite also experiencing design limitations and minor differences in patient profiles, all arrive at positive conclusions for improved nutrition and reduced inpatient stays among screened infants. We speculate that the early detection, treatment, and perhaps prevention of CF related illness in infants diagnosed early may break the cycle of infection and failure to thrive which previously alerted a medical diagnosis in symptomatic (pre-screened) patients. It may therefore be appropriate for screening programmes to focus on the diagnosis of more severe or classic cases of CF ( $\triangle \mathrm{F} 508$ or common population specific mutations). ${ }^{4527} 28$ If neonatal screening programmes for $\mathrm{CF}$ are to be more widely adopted, whether screening will provide any benefit to patients with "milder" disease genotypes or phenotypes needs to be considered, as many patients in these categories maintain near normal lung function and remain PS into adulthood. ${ }^{29} 30$

The advantages in nutrition and pulmonary function shown by the screened cohort in this study are yet to be explained. Preliminary results from a randomised controlled study of continuous prophylactic antibiotic treatment started in the neonatal period ${ }^{31}$ have suggested that this treatment may benefit screened patients. However, benefits may equally be derived from the early and appropriate introduction of nutritional and pancreatic enzyme replacement in the screened group.

We have not addressed the balance of benefit or harm for the psychological or social aspects of neonatal screening for CF in this report, but are aware that any possible benefits must be weighed against the needs and reactions of parents, costs to the State, and above all, the wellbeing of the infant. Further studies are required to determine how early diagnosis and management influence later clinical, psychological, and social outcomes, and whether clinical benefits can be maintained into future adolescence and adulthood. For countries contemplating the introduction of neonatal screening for $\mathrm{CF}$, its introduction to some areas in a cluster randomised design may help to resolve some of these issues.

We acknowledge Gwen Chalmers, Cheryl Frazer, and Petra Macaskill for their kind assistance in the preparation of this paper.

1 Wilcken B. Newborn screening for cystic fibrosis: its evolution and a review of the current situation. Screening 1993;2:43-62.

2 Farrell PM, Mischler EH. Newborn screening for cystic fibrosis: The cystic fibrosisneonatal screening study group. Adv Pediatr 1992;39:35-70.

3 Heeley AF, Bangert SK. The neonatal detection of cystic fibrosis by measurement of immunoreactive trypsin in fibrosis by measurement of immunoreactiv

4 Gregg RG, Wilfond BS, Farrell PM, Laxova A, Hassemer D, Mischler EH. Application of DNA analysis in a population screening program for neonatal diagnosis of cystic fibrosis (CF): comparison of screening protocols. Am f Hum Genet 1993;52:616-26.

5 Wilcken B, Wiley V, Sherry G, Bayliss U. Neonatal screening for cystic fibrosis: a comparison of two strategies for case detection in 1.2 million babies. $\mathcal{f}$ Pediatr 1995;127:965-70

6 Waters DL, Dorney SFA, Gaskin KJ, Gruca MA, O'Halloran M, Wilcken B. Pancreatic function in infants identified as having cystic fibrosis in a neonatal screening program. N Engl f Med 1990;322:303-8.

7 Ad Hoc Committee Task Force on Neonatal Screening, Cystic Fibrosis Foundation. Neonatal screening for cystic fystic Fibrosis Foundation. Neonatal screening

8 Al-Jader LN, Goodchild MC, Ryley HC, Harper PS. Attitudes of parents of cystic fibrosis children towards 
neonatal screening and antenatal diagnosis. Clin Genet 1990:38:460-5.

9 Boland C, Thompson NL. Effects of newborn screening of cystic fibrosis on reported maternal behaviour. Arch Dis Child 1990;65:1240-4.

10 Helton JL, Harmon RJ, Robinson N, Accurso FJ. Parental attitudes toward newborn screening for cystic fibrosis. Pediatr Pulmonol 1991;Suppl 7:23-8.

11 Perobelli S, Faraguna D, Giglio L, et al. False positive screening for cystic fibrosis: reactions in parents and attitudes of professionals. In: Travert G, ed. Mucoviscidose: Dépistage Néonatal et Prise en Charge Précoce. Caen: CHRU de Caen, 1988:203-14.

12 Marcus MS, Sondel SA, Farrell PM, et al. Nutritional status of infants with cystic fibrosis associated with early diagnosis and intervention. Am 7 Clin Nutr 1991;54:578-85.

13 Reardon MC, Hammond KB, Accurso FJ, et al. Nutritional deficits exist before 2 months of age in some infants with cystic fibrosis identified by screening test. $\mathcal{F}$ Pediatr 1984; 105:271-4.

14 Holliday KE, Allen JR, Waters DL, Gruca MA, Thompson SM, Gaskin KJ. Growth of human milk-fed and formula-
fed infants with cystic fibrosis. 7 Pediatr 1991;118:77-9.

15 Wilcken B, Chalmers G. Reduced morbidity in patients with cystic fibrosis detected by neonatal screening. Lancet $1985 ; 2: 1319-21$

16 Mastella G, Barlocco EG, Antonacci B, et al. Is neonatal screening for cystic fibrosis advantageous? The answer of wide 15 years follow-up study. In: Travert G, ed. Mucoviscidose: Dépistage Néonatal et Prise en Charge Précoce. Caen: CHRU de Caen, 1988:127-43.

17 Dankert-Roelse JE, te Meerman GJ. Long term prognosis of patients with cystic fibrosis in relation to early detection by neonatal screening in a cystic fibrosis centre. Thorax 1995;50:712-18

18 Chatfield S, Owen G, Ryley HC, et al. Neonatal screening for cystic fibrosis in Wales and the West Midlands: clinical assessment after five years of screening. Arch Dis Child 1991;66:29-33.

19 Mischler E, Farrell P, Bruns T, et al. Progress report: Neonatal screening for cystic fibrosis in Wisconsin. Wis Meonatal screening for
20 Farrell PM, Aronson RA, Hoffman G, Laessig RH. Newborn screening for cystic fibrosis in Wisconsin: first application of population-based

21 Farrell PM, Kosorok MR, Laxova A, et al. Nutritional benefits of neonatal screening for cystic fibrosis. $N$ Engl F Med 1997;337:963-9.

22 Corey M, Levison H, Crozier D. Five-to seven-year course of pulmonary function in cystic fibrosis. Am Rev Respir Dis 1976;114:1085-92.

23 Dibley MJ, Goldsby JB, Staehling NW, Trowbridge FL. Development of normalised curves for the international growth reference: historical and technical considerations. Am $\mathcal{F}$ Clin Nutr 1987;46:736-48.

24 Zeger SL, Liang K-Y, Albert PS. Models for longitudinal data: a generalized estimating equation approach. Biometrics 1988;44:1049-60.

25 WHO: Annex 3: reference data for the weight and height of children. In: Measuring change in nutritional status: guidelines for assessing the nutritional impact of supplementary guidelines for assessing the nutritional impact of supplementary
feeding programs for vulnerable groups. Geneva: World feeding programs for vulnerable grou

26 Kristidis P, Bozon D, Corey M, et al. Genetic determination of exocrine pancreatic function in cystic fibrosis. $A m \mathcal{F}$ Hum Genet 1992;50:1178-84.

27 Ranieri E, Lewis BD, Gerace RL, et al. Neonatal screening for cystic fibrosis using immunoreactive trypsin and direct gene analysis: four years' experience. BMf 1994;308:1469-72.

28 Spence WC, Paulus-Thomas J, Orenstein DM, Naylor EW. Neonatal screening for cystic fibrosis: addition of molecular diagnostics to increase specificity. Biochem Med Metab Biol 1991;46:105-9.

29 Strong TV, Smit LS, Turpin SV, et al. Cystic fibrosis gene mutation in two sisters with mild disease and normal sweat electrolyte levels. N Engl f Med 1991;325:1630-34.

30 The Cystic Fibrosis Genotype-Phenotype Consortium. Correlation between genotype and phenotype in patients Correlation between genotype and phenotype in patien
with cystic fibrosis. N Engl ₹ Med 1993;329:1308-13.

31 Weaver LT, Green MR, Nicholson K, et al. Prognosis in cystic fibrosis treated with continuous flucloxacillin from the neonatal period. Arch Dis Child 1994;70:84-9. 